\title{
An Early Miocene microtoid cricetid rodent from the Junggar Basin of Xinjiang, China
}

Olivier Maridet, Wenyu Wu, Jie Ye, Jin Meng, Shundong Bi, and Xijun Ni

Acta Palaeontologica Polonica 59 (1), 2014: 1-7 doi: http://dx.doi.org/10.4202/app.2012.0007

Microtoid cricetids are widely considered to be the ancestral form of arvicoline rodents, a successful rodent group including voles, lemmings and muskrats. The oldest previously known microtoid cricetid is Microtocricetus molassicus from the Late Miocene (MN9, ca. 10-11 Ma) of Europe. Here, we report a new microtoid cricetid, Primoprismus fejfari gen. et sp. nov., from the Junggar Basin of Xinjiang, northwestern China. The rodent assemblage found in association with this specimen indicates a late Early Miocene age, roughly estimated at 18-17 Ma, and thus more than 6 million years older than M. molassicus. While morphological comparisons suggest that the new taxon is most closely related to M. molassicus, it differs from the latter in a striking combination of primitive characters, including a lower crown, smaller size, a differentiated posterolophid and hypolophid, a faint anterolophid, the absence of an ectolophid, and the presence of a stylid on the labial border of the tooth. Arid conditions prevailing across the mid-latitude interior of Eurasia during the Early Miocene, enhanced by the combined effects of the Tibetan uplift and the gradual retreat of the Tethys Ocean, likely played a role in the appearance of grasslands, which in turn triggered the evolution of microtoid cricetids and, ultimately, the origin of arvicoline rodents.

Key words: Mammalia, Rodentia, Cricetidae, Arvicolinae, Miocene, Junggar, China, Central Asia.

Olivier Maridet [olivier.maridet@ivpp.ac.cn], Wenyu Wu [wuwy242@hotmail.com ], Jie Ye [jieye@ hotmail.com], Shundong Bi [shundong.bi@iup.edu] and Xijun Ni [nixijun@ivpp.ac.cn ] corresponding author, Key Laboratory of Evolutionary Systematics of Vertebrates, Institute of Vertebrate Paleontology and Paleoanthropology, Chinese Academy of Sciences Beijing 100044, P.R. China; Jin Meng [jmeng@amnh.org], Division of Paleontology, American Museum of Natural History, History, Central Park West at 79th Street, New York, NY 10024, USA.

This is an open-access article distributed under the terms of the Creative Commons Attribution License (for details please see creativecommons.org), which permits unrestricted use, 
distribution, and reproduction in any medium, provided the original author and source are credited.

Fof Full text $(239.9 \mathrm{kB})$ 